\title{
How Do Children with Autism Spectrum Disorder Encode and Reproduce Visuospatial Stimuli?: Investigation into Visuospatial Processing Abilities and Styles
}

\author{
So Yoon Kim¹, Da-Yea Song', Young Ah Kim¹, Guiyoung Bong', \\ Jong-myeong Kim ${ }^{1}$, Joo Hyun Kim¹, and Hee Jeong Yoo ${ }^{1,2} \bowtie$ \\ ${ }^{1}$ Department of Psychiatry, Seoul National University Bundang Hospital, Seongnam, Republic of Korea \\ ${ }^{2}$ Department of Psychiatry, Seoul National University College of Medicine, Seoul, Republic of Korea
}

\begin{abstract}
Objective The purpose of this study was to examine the visuospatial processing abilities of children with autism spectrum disorder (ASD) using the Rey Osterrieth Complex Figure (ROCF).

Methods One-hundred thirty-four children with ASD [mean age (MA)=113.56 months], 150 siblings of children with ASD (MA= 111.67 months), and 55 typically developing (TD) children (MA=109.02 months) were included in this study. During their one-time visit, participants completed the ROCF, various autism diagnostic assessments, and the Korean-Leiter International Performance ScaleRevised. Repeated-measures Analysis of Covariance (ANCOVA) and post-hoc Tukey-Kramer comparisons were computed to compare the ROCF scores. Partial correlations and multiple regressions were computed to examine the association between ROCF scores and the severity of autistic symptoms, as measured by the Autism Diagnostic Interview-Revised (ADI-R) among children with ASD.

Results There were significant main effects of the analysis group in Structural and Incidental Accuracy, Error, and Style. More siblings than TD children drew in a part-oriented way, but the performance of the sibling group was comparable or superior to that of the TD group in all parameters. Social Interaction scores of children with ASD were significantly associated with Organization scores in Copy condition. Whether or not a child drew in the Part-Oriented style significantly predicted his/her repetitive and restricted behavior scores.

Conclusion The findings add to the evidence for altered visuospatial processing patterns of ASD as a potential inherent and genetic trait and suggest that this particular cognitive style should not be considered as a deficit. Educational and theoretical implications are discussed.

Psychiatry Investig 2020;17(11):1105-1117
\end{abstract}

Key Words ASD, ROCF, Central coherence, Visuospatial processing.

\section{INTRODUCTION}

An altered visuospatial processing style, which favors perceiving complex stimuli locally, has been reported to be one of the characteristics of autism spectrum disorder (ASD). ${ }^{1}$ The local processing bias in ASD was initially supported by empirical studies reporting the superior performance of individuals with ASD to that of typically developing (TD) individuals on

Received: May 21, 2020 Revised: June 25, 2020

Accepted: September 5, 2020

$\triangle$ Correspondence: Hee Jeong Yoo, MD, PhD

Department of Psychiatry, Seoul National University Bundang Hospital, Seoul National University College of Medicine, 82 Gumi-ro 173beon-gil, Bundanggu, Seongnam 13620, Republic of Korea

Tel: +82-31-787-7436, Fax: +82-31-787-4058, E-mail: hjyoo@snu.ac.kr

(c) This is an Open Access article distributed under the terms of the Creative Commons Attribution Non-Commercial License (https://creativecommons.org/licenses/by$\mathrm{nc} / 4.0$ ) which permits unrestricted non-commercial use, distribution, and reproduction in any medium, provided the original work is properly cited. the embedded figures test (EFT), which involves distinguishing particular shapes within larger, complex figures. ${ }^{2}$ Several prominent accounts such as the Weak Central Coherence (WCC) theory and the Enhanced Perceptual Functioning (EPF) theory have been suggested to account for the atypical visuospatial processing in ASD.

The classical WCC theory contends that individuals with ASD have an inherent perceptual-cognitive propensity to process incoming stimuli locally at the expense of attending to contextual information that can help understand the global, higher-level meaning of a situation. ${ }^{1}$ Over time, the WCC theory has been evolved to suggest the independence of local and global processing within individuals with ASD. ${ }^{3}$ Booth ${ }^{4}$ reported that local processing abilities of TD individuals were positively correlated with their global processing abilities, but the trade-off pattern between local and global processing abilities 
was shown within individuals with ASD. The EPF theory contends that global processing is mandatory and automatic for the general population, while it is optional for individuals with ASD. ${ }^{5}$ Therefore, individuals with ASD can process visuospatial stimuli globally when explicitly instructed or when it is advantageous to do so, but they tend not to do so automatically or naturally. ${ }^{5}$

While these theoretical accounts have been raised, it is also possible that genetic factors may account for the altered visuospatial processing style in ASD. Spencer et al. ${ }^{6}$ demonstrated that children with ASD and their unaffected siblings, who share $50 \%$ of the genes on average, ${ }^{7}$ exhibited a similar pattern of atypical brain activation during the EFT. Genetic and epidemiological data show that the relatives of individuals with ASD tend to share autistic traits that are similar to, but not as severe as those of individuals with ASD, a phenomenon referred to as "Broader Autism Phenotype" (BAP). ${ }^{8}$ The findings of Spencer et al. $^{6}$ support the claim that the visuospatial processing style is a potential candidate for an endophenotype of ASD. However, very few studies have examined the visuospatial processing style of unaffected siblings of children with ASD.

While the underlying mechanism remains unclear, recent empirical studies comparing the visuospatial processing abilities of individuals with ASD to those of TD individuals have yielded inconsistent and often contradictory results. ${ }^{9-11}$ Previous studies were also limited by their small sample sizes ranging from 6 to 5011 and were based on the ability-inability framework, which focuses on the reaction time to replicate the components or whether an individual with ASD can correctly reproduce components of a figure. ${ }^{11}$ Van der Hallen et al. ${ }^{11}$ found limitations in such approaches and suggest future research would benefit from including more measures that qualitatively investigate the process and style.

Rey Osterrieth Complex Figure (ROCF) ${ }^{12,13}$ is a neuropsychological test assessing visuospatial processing abilities and style, and Developmental Scoring System (DSS) of the ROCF allows for both quantitative and qualitative analysis. ${ }^{14,15}$ During the ROCF, participants are presented with a complex and abstract geometric figure and then instructed to reproduce the image in a series of conditions. The DSS provides five parameters of visuospatial abilities: Style, Structural Accuracy, Incidental Accuracy, Error, and Organization. Supplementary Table 1 (in the online-only Data Supplement) for detailed definitions and scoring methods.

Studies using the ROCF test consistently have shown that individuals with ASD tend to rely on part-oriented processing Styles more than TD groups. ${ }^{15-18}$ However, less consistent results have been reported regarding the performance of individuals with ASD on the ROCF test, as measured by Accuracy, Error, and Organization variables. ${ }^{15,18-20}$ Meanwhile, previous studies have also noted that the organizational and planning skills of TD children improve with age as they start to adopt more global processing strategies. But unlike the TD children, this developmental shift was not observed in children with ASD. ${ }^{18,21}$

Whether or not children with ASD have developed the global visuospatial processing strategies may influence their observable behaviors. However, Eylen et al. ${ }^{22}$ found that the Style variable, as measured by the ROCF, was not associated with the social interactions and restricted and repetitive behaviors scores (RRBs) in the combined ASD and TD sample. ${ }^{22}$ To our knowledge, no other study has examined the association between the ROCF and autistic traits. We, therefore, review empirical evidence that investigated local processing abilities and three domains of behavioral symptoms of ASD, Social Interactions, Verbal Communications, and RRBs, to support our understanding of how ROCF scores might be associated with autistic symptoms.

First, Brunsdon and Happe ${ }^{23}$ suggest that local processing bias may be related to social abilities because understanding social interactions necessitate the integration of local and discrete contextual information (e.g., facial expression). Empirical evidence examining the association between local processing style and Social Interaction have been inconsistent. ${ }^{24-26}$ In regards to verbal communication, Noens and BerckelaerOnnes ${ }^{27}$ suggested that difficulties in interrelating incoming stimulus may contribute to a preference for a gestalt verbal language style (i.e., language as memorized entire units). ${ }^{28}$ Also, common language characteristics of individuals with ASD such as echolalia, pronoun reversal, and neologisms may be consequences of a local processing style. ${ }^{27}$ While Pellicano et al. ${ }^{26}$ reported that the central coherence skills were not significantly correlated with the communication domain of the Autism Diagnostic Interview-Revised (ADI-R), ${ }^{29}$ we are not aware of any studies that specifically examined the association between Verbal Communication and local processing style of ASD. Finally, Frith1 posits that the predisposition for discrete details can account for insistence on sameness and narrow interests because attending to a piece of detail requires less effort than extracting coherent meaning from a whole picture. However, the results of the few existing studies have been inconsistent. Chen et al. ${ }^{30}$ found a significant association between a detailfocused visuospatial processing style and the degree of repetitive behaviors in children with ASD, while Drake et al. ${ }^{31}$ did not.

In sum, despite the abundant theoretical accounts that emphasize local processing style as one of the key characteristics of ASD and its link with autistic symptoms, existing studies have not reached a consensus on the unique visuospatial processing style of children with ASD. Therefore, we used the ROCF, which provides multidimensional, standardized, and struc- 
tured indices of visuospatial processing abilities and style, with a relatively large number of participants to understand the visuospatial processing style of children with ASD. Studying the visuospatial processing styles of children with ASD may ultimately aid formatting materials and environments to be easily perceived and processed by children with ASD. Specifically, we pursued the following two aims:

\begin{abstract}
Aim 1
To examine if there are significant differences in ROCF scores among the analysis groups (ASD, TD, and siblings of children with ASD).

Consistent with the theoretical accounts of local visuospatial processing bias in ASD, we hypothesized that more children with ASD would show a more part-oriented processing style and that children with ASD would have more difficulties copying and reproducing the target figure (i.e., score lower in Organization, Error and Accuracy parameters) than the TD group. We also hypothesized that the sibling group would exhibit BAPs (i.e., similar patterns of visuospatial processing abilities and patterns with children with ASD) and score lower than the TD group across all parameters, but score higher than the ASD group. Relatedly, we hypothesized that similar patterns would be observed in the number of siblings who show a more part-oriented processing style.
\end{abstract}

\section{$\operatorname{Aim} 2$}

To examine if the ROCF scores are associated with Social Interaction, Verbal Communications, and RRBs in children with ASD.

Due to the lack of consensus among studies examining the relations between local visuospatial processing bias and autistic symptoms in children with ASD, we considered the second research question to be exploratory.

\section{METHODS}

\section{Participants}

The participants were a subset from a larger study examining associations between genetic compositions and various autistic traits. All data collection procedures (IRB no: B-1703/388-303, B-1106/129-009, B-0807/059-018) and retrospective analyses of collected data (IRB no: B-1912/582-107) were approved by the Institute Review Board (IRB). Participants in the larger study were recruited and referred from the Child Psychiatric Clinic of Seoul National University Bundang Hospital by two board-certified psychiatrists (the 4th author and the corresponding author of this study). The board-certified psychiatrists initially screened all children who came to the authors' clinic based on Diagnostic and Statistical Manual of Mental Disorders, 5th edition (DSM-5) and suggested if they are willing to participate in the larger study.

A total of 339 participants were included in the study, including 134 children with ASD, 150 siblings of children with ASD, and 55 TD children, who did not have a sibling with ASD. Of 150 siblings of children with ASD, 77 were the siblings of the 134 probands included in the study. Consistent with the age range that the DDS can be applied to, only participants who were 5 - to 15 -year-olds were included. There were no significant differences in age among the groups. Detailed demographic characteristics of each group are reported in Table 1.

Table 1. Participant characteristics

\begin{tabular}{lcccc}
\hline \multicolumn{1}{c}{ Demographic characteristics } & ASD & Sibling & TD & $\begin{array}{c}\text { p-value from one-way } \\
\text { between group ANOVA }\end{array}$ \\
\hline Number & 134 & 150 & 55 & N/A \\
Percentage of male (\%) & 88.06 & 41.33 & 52.23 & N/A \\
Age in months (SD) & $113.54(27.09)$ & $111.67(31.91)$ & $109.02(21.96)$ & 0.61 \\
\cline { 2 - 4 } & & Mean (SD) & $<0.01$ \\
Standardized Leiter-R & $103.80(53.26)$ & $127.20(64.19)$ & $117.67(18.06)$ & $<0.01$ \\
ADI-R diagnostic algorithm score - social Interaction* & $16.36(6.72)$ & $2.36(2.55)$ & $1.62(1.12)$ & $<0.01$ \\
ADI-R diagnostic algorithm score - communication* & $16.69(6.39)$ & $1.61(1.83)$ & $1.36(1.52)$ & $<0.01$ \\
ADI-R diagnostic algorithm score - RRB* & $5.25(2.63)$ & $0.50(1.16)$ & $0.44(.76)$ & $<0.01$ \\
ADOS-2 social interaction ${ }^{\dagger}$ & $7.96(3.14)$ & $1.67(2.11)$ & $1.25(1.60)$ & $<0.01$ \\
ADOS-2 communication ${ }^{\dagger}$ & $2.97(1.19)$ & $1.17(1.22)$ & $1.12(.77)$ & $<0.01$ \\
ADOS-2 RRB $^{\dagger}$ & $4.07(4.73)$ & $0.08(.31)$ & $0.0(0.0)$ & $<0.01$ \\
Social responsiveness scale-2 $^{*}$ & $88.23(30.82)$ & $27.10(22.91)$ & $21.84(17.13)$ & \\
\hline
\end{tabular}

*diagnostic algorithm score based on 4-5 years of age, ${ }^{\dagger}$ scores were converted to ADOS-2 algorithm if ADOS was conducted. ASD: autism spectrum disorder, TD: typically developing, SD: standard deviation, ADI-R: Autism Diagnostic Interview-Revised, ADOS-2: Autism Diagnostic Observation Schedule-2, N/A: not applicable, ANOVA cannot be computed, SD: standard deviation, RRB: repetitive and restricted behavior 


\section{Study procedures}

All collected data were retrospectively analyzed to address the research aims of the present study. Upon informed parental consent, participants completed a battery of tests composed of the ROCF during a one-time visit to the authors' laboratory. The tests included the Korean translation of Autism Diagnostic Observation Schedule (ADOS) ${ }^{32}$ and the ADOS-2, ${ }^{33,34}$ the Korean translation of ADI-R, ${ }^{29,35}$ the Social Responsiveness Scale-the Second Edition (SRS-2), ${ }^{36}$ and the Korean-Leiter International Performance Scale-Revised (K-Leiter-R). ${ }^{37}$ The ROCF and K-Leiter-R were administered and scored by trained graduate students under the supervision of professional clinical psychologists. The reliability of all administrations and assessments of the ROCF was regularly checked and closely monitored by professional clinical psychologists to make sure they closely adhere to the DSS instructions. ${ }^{14}$ ADOS-2 were administered by the research-certified researcher (GB; the fourth author of this study) and trained research assistants. All research assistants worked at the same lab with GB on a daily basis, and the inter-rater reliability between research assistants and GB was maintained to be above $80 \%$. Assessments administered by research assistants were video recorded and double-checked by GB. The diagnostic status of all participants was confirmed with best clinical judgments of experienced psychiatrists based on the ADOS-2, ADI-R and SRS-2 scores. All participants with ASD had either ADOS-2 or ADI-R scores higher than the cutoff points and met the DSM-5 criteria; all children in the TD and sibling group scored below the clinical threshold of ADI-R and ADOS-2.

\section{Measurements}

\section{ROCF}

The ROCF test consists of three conditions in which participants are asked to directly copy the figure (i.e., Copy), then draw it from memory immediately after its removal [i.e., Immediate Recall (IR)], and finally draw it again 20-30 minutes after the initial copying [i.e., Delayed Recall (DR)]. The DSS, which takes into account the participants' motor abilities, scores participants' performance on five parameters of the ROCF, Style, Structural Accuracy, Incidental Accuracy, Error ${ }^{\mathrm{a}}$ and Organization for each of the three conditions.

\section{ADI-R}

The ADI-R, a standardized, structured caregiver interview used for diagnosing ASD, ${ }^{29}$ was used to examine the correlation between symptom severity and ROCF scores. The Korean translated version of ADI-R, which was approved by the West-

aThe Accuracy measured the number of elements reproduced, and the actual accuracy of the reproduced figures captured by the Error variable. ern Psychological Services (WPS), was used in this study. ${ }^{35}$ This study utilized the current algorithm to examine the association between their current behavior and ROCF scores.

\section{ADOS and ADOS-2}

ADOS and ADOS- $2^{32,33}$ are play-based standardized instruments used to diagnose ASD with various structured and semistructured activities that elicit social interactions between the examiner and the person who is being assessed. The Korean translation of the ADOS-2, which was approved by its publisher, Western Psychological Services, was used in this study. The ADOS was conducted for children who participated in the study before the ADOS-2 was published in South Korea.

\section{SRS-2}

The SRS- $2^{36}$ is an ASD screening instrument, completed by caregivers to measure a child's autistic symptom severity. It consists of 65 items, which is rated from 1 (not at all) to 4 (almost always). We received permission to use the Korean translated version of the SRS-2 from its copyright holder, WPS Publish. Although the SRS has not been standardized in Korea, Cronbach's a value of the Korean translation of SRS-2 was reported to be $0.96 .^{38}$

\section{K-Leiter-R}

The K-Leiter- $\mathrm{R}$ is a standardized test that measures the nonverbal performance intelligence of individuals between the ages of 2 and 20 years and 11 months. The K-Leiter-R consists of four subscales: Matching, Associated Pairs, Forward Memory, and Attention Sustained. The K-Leiter-R was chosen because it has been standardized in Korean children with sufficient validity. ${ }^{39}$ Also, because the test does not require participants to use or comprehend speech, it may be particularly useful for children with ASD who do not have sufficient verbal comprehension skills to understand instructions for the Wechsler Intelligence Scale for Children-Revised (WISC-R). ${ }^{40}$ Additionally, because few tasks of the WISC-R (e.g., Block Design and Object Assembly) measure central coherence skills, the standardized scores of the K-Leiter-R were utilized to measure the performance Intelligence Quotient (IQ).

\section{Data analyses}

Prior to the analysis, the Style variable was dummy-coded. A value of one was assigned for the Style category exhibited in a condition and a zero was assigned for remaining categories within the condition. For instance, a participant who copied the figure in a part-oriented style was given a value of 1 for the Part-Oriented style in the Copy condition and 0 for the remaining categories.

To address the first research question, each of the ROCF pa- 
rameter scores was analyzed with a repeated-measure Analysis of Covariance (ANCOVA) with analysis groups as betweensubject factors and age and performance IQ as covariates. Each dummy-coded style variable was analyzed using ANCOVA with the same between- and within-subject factors and covariates entered. Post-hoc pairwise comparisons using the TukeyKramer adjustment with Box's conservative epsilon correction, which corrects for multiple hypotheses testing of samples with unequal sizes, were computed for variables significant in ANCOVA. In the Style domain, variables at the extreme ends (whether or not participants' style was Part-Oriented or Configurational) were examined to limit the number of hypotheses tested.

Among the data of 339 participants included to investigate the first research question, the data from the children with ASD were separately analyzed to address the second aim of the study. Partial correlations between the 15 variables (i.e., five parameters for each of Copy, IR, and DR condition) and the three ADI-R scores (i.e., Reciprocal Social Interaction, Verbal Communication, and RRB) were computed, while controlling for the standardized K-Leiter-R scores. Because we were particularly interested in children's ability to communicate via speech, the current algorithm scores that measure verbal communication were included. To examine the associations with dichotomous Style variables, three sets of six linear robust regressions with the 'vce(robust)' option in Stata, ${ }^{41}$ which corrects for violations of distributional assumptions, were conducted; each set modeled Reciprocal Social Interaction, Verbal Communication, and RRB, separately as outcome variables. For each of these, a dummy coded Style variable and the standardized $\mathrm{K}$-Leiter-R score were entered as predictors. Holm-Bonferroni's corrections were used to account for the multiple hypothesis testing.

Additionally, to examine in detail how RRBs are uniquely associated with the ROCF scores of children with ASD, the RRB domain was further divided into four subdomains: encompassing preoccupation or circumscribed pattern of interest, compulsive adherence to routines or rituals, motor mannerisms, and preoccupation with parts of objects or non-functional elements of material. Another set of regressions was computed to predict each of the RRB subdomains with the ROCF variables that were significantly associated with overall $R R B$ scores, while controlling for the performance IQ. All data analyses were computed using Stata statistical software. ${ }^{41}$

\section{RESULTS}

\section{Differences in ROCF scores among analysis groups}

Table 2 presents the mean and standard deviation of each score for all three analysis groups. There was a significant effect of the condition in the Configurational variable, $\mathrm{F}(2,612)=$ $3.54, \mathrm{p}<0.001, \eta_{\mathrm{p}}{ }^{2}=0.04$, but not in the Part-Oriented variable, $\mathrm{F}(2,612)=0.07, \mathrm{p}=0.68, \eta_{\mathrm{p}}{ }^{2}<0.01$ (Table 3 ). The post-hoc TukeyKramer test in the Configurational variable showed that there was no significant difference between the two Recall conditions, $\mathrm{p}>0.05$ [mean differences $(\mathrm{MD})=0.03$ ], and the proportion of the number of participants who drew in a Configurational way was significantly lower in Copy conditions compared to the IR and DR conditions, both $\mathrm{p}<0.05(\mathrm{MD}=0.17$ and 0.14 , respectively). There was a main effect of the analysis group for Configurational and Part-Oriented styles, $\mathrm{F}(2,612)=8.29$, $\mathrm{p}<0.001, \eta_{\mathrm{p}}{ }^{2}=0.06$ and $\mathrm{F}(2,612)=10.02 \mathrm{p}<0.001, \eta_{\mathrm{p}}{ }^{2}=0.09$, respectively, when controlling for condition and age.

The proportion of the number of participants who drew in a Part-Oriented style was significantly higher in the ASD group than in the sibling group $(\mathrm{MD}=0.13)$ and was lowest in the TD group $(\mathrm{MD}=0.16)$ (Figure 1$)$. The opposite pattern was reported in the Configurational domain, in which the number of participants who drew in a Configurational style was lowest in the ASD group and highest in the TD group, all $\mathrm{p}<0.05$ (Figure 2). The results from Tukey-Kramer Comparisons for Conditions and Analysis Group are presented in Supplementary Tables 2 and 3 (in the online-only Data Supplement), respectively.

There was a significant interaction effect between the analysis group and condition only in the Configurational parameter, $\mathrm{F}(4,612)=1.62, \mathrm{p}=0.02, \eta_{\mathrm{p}}{ }^{2}=0.02$. In all three analysis groups, there was a general trend that the proportion of the number of participants who drew in the Configurational style increased from Copy to IR condition, $\mathrm{MD}=0.15$ in the ASD group, $\mathrm{p}<$ $0.05 ; \mathrm{MD}=0.18$ in the sibling group, $\mathrm{p}<0.05$; and $\mathrm{MD}=0.15$ in the TD group, approaching significance (i.e., studentized range critical value=2.90). From the Copy to DR condition, the proportion of the number of participants who drew in a Configurational style significantly increased in sibling $(\mathrm{MD}=0.19)$ and TD group $(\mathrm{MD}=0.21)$, both $\mathrm{p}<0.05$, but no significant change from the Copy to DR condition was reported in the ASD group $(\mathrm{MD}=0.02), \mathrm{p}>0.05$. Within the Recall conditions, the number of children in the TD and sibling groups who drew in the Configurational style did not differ between the two Recall conditions ( $\mathrm{MD}=0.01$ and 0.07 , respectively), both $\mathrm{p}>0.05$, but the number of children with ASD who drew in a Configurational style significantly decreased from IR to $\mathrm{DR}(\mathrm{MD}=0.14), \mathrm{p}<0.05$.

There were significant main effects of condition for Structural Accuracy, $\mathrm{F}(2,612)=121.61, \mathrm{p}<0.001, \eta_{\mathrm{p}}{ }^{2}=0.28$, and Incidental Accuracy, $\mathrm{F}(2,612)=486.44 ; \mathrm{p}<0.001, \eta_{\mathrm{p}}{ }^{2}=0.61$. Post-hoc tests showed that both Accuracy scores in the Copy condition were significantly higher than those in the IR (MD for Structural and Incidental Accuracy=4.96 and 13.61, respectively), both $\mathrm{p}<0.05$, and DR conditions (MD for Structural and Incidental Accuracy=5.02 and 13.63, respectively), both $\mathrm{p}<0.05$, 
Table 2. Group means and proportions on ROCF parameters

\begin{tabular}{|c|c|c|c|c|}
\hline \multirow{2}{*}{ Parameter } & \multirow{2}{*}{ Conditions } & ASD & Sibling & $\mathrm{TD}$ \\
\hline & & \multicolumn{3}{|c|}{ Means (SD) } \\
\hline \multirow[t]{3}{*}{ Organization } & Copy & $6(4.20)$ & $6.85(4.12)$ & $6.65(3.67)$ \\
\hline & IR & $4.78(3.97)$ & $5.67(4.87)$ & $5.25(4.24)$ \\
\hline & $\mathrm{DR}$ & $4.92(4.17)$ & $5.72(4.57)$ & $5.67(4.52)$ \\
\hline \multirow[t]{3}{*}{ Structural accuracy } & Copy & $20.84(6.96)$ & $22.61(4.90)$ & $22.93(4.71)$ \\
\hline & IR & $16.09(8.25)$ & $17.35(8.02)$ & $18.02(7.05)$ \\
\hline & $\mathrm{DR}$ & $15.19(8.51)$ & $18.01(7.56)$ & $17.70(7.14)$ \\
\hline \multirow[t]{3}{*}{ Incidental accuracy } & Copy & $31.08(11.05)$ & $35.03(6.92)$ & $36.75(4.02)$ \\
\hline & IR & $17.24(12.43)$ & $21.53(9.94)$ & $22.53(0.48)$ \\
\hline & $\mathrm{DR}$ & $17.31(12.44)$ & $21.41(9.36)$ & $22.48(9.36)$ \\
\hline \multirow[t]{4}{*}{ Error } & Copy & $1.38(2.01)$ & $1.21(1.96)$ & $1.25(1.95)$ \\
\hline & IR & $1.77(2.76)$ & $1.34(1.66)$ & $2.53(2.69)$ \\
\hline & $\mathrm{DR}$ & $1.69(8.51)$ & $1.51(1.73)$ & $2.5(2.56)$ \\
\hline & & \multicolumn{3}{|c|}{ Proportion (SD) } \\
\hline \multirow[t]{3}{*}{ Part-oriented } & Copy & $0.32(0.47)$ & $0.22(0.42)$ & $0.05(0.23)$ \\
\hline & IR & $0.33(0.47)$ & $0.23(0.42)$ & $0.05(0.23)$ \\
\hline & $\mathrm{DR}$ & $0.40(0.49)$ & $0.19(0.39)$ & $0.06(0.23)$ \\
\hline \multirow[t]{3}{*}{ Configurational } & Copy & $0.30(0.46)$ & $0.33(0.25)$ & $0.51(0.50)$ \\
\hline & IR & $0.45(0.50)$ & $0.52(0.50)$ & $0.65(0.48)$ \\
\hline & DR & $0.32(0.47)$ & $0.53(0.50)$ & $0.72(0.45)$ \\
\hline
\end{tabular}

ASD: autism spectrum disorder, TD: typically developing, SD: standard deviation, ROCF: Rey-Osterrieth Complex Figure test, IR: immediate recall, DR: delayed recall

and there were no significant differences between IR and DR conditions (MD for Structural and Incidental Accuracy $=0.06$ and 0.03 , respectively), both $p>0.05$. There were main effects of the analysis group for Structural Accuracy and Incidental Accuracy, $\mathrm{F}(2,612)=6.59, \mathrm{p}=0.002, \eta_{\mathrm{p}}{ }^{2}=0.04$ and $\mathrm{F}(2,612)=$ 14.23, $\mathrm{p}<0.001, \eta_{\mathrm{p}}{ }^{2}=0.08$ (Figures 3 and 4). Post-hoc pairwise comparisons indicated that the scores of the ASD group in Structural Accuracy and Incidental Accuracy were significantly lower than for those of the Sibling and TD groups (MD for Structural Accuracy=1.77 and 1.98 and MD for Incidental Accuracy $=3.66$ and 4.86 , respectively), both $\mathrm{p}<0.05$. There were no significant differences between TD and sibling groups (MD for Structural and Incidental Accuracy $=0.21$ and 1.20, respectively), both $\mathrm{p}>0.05$.

There was a main effect of condition in Error, $\mathrm{F}(2,612)=$ $19.15, \mathrm{p}<0.001, \eta_{\mathrm{p}}{ }^{2}=0.06$. The Error scores for both IR and DR conditions were significantly higher than those for the Copy condition ( $\mathrm{MD}=0.42$ and 0.46 , respectively) $\mathrm{p}<0.05$, but there were no significant differences between IR and DR conditions $(\mathrm{MD}=0.04), \mathrm{p}>0.05$ (Figure 5). There was a significant main effect of analysis group, $\mathrm{F}(2,612)=3.87, \mathrm{p}=0.02, \eta_{\mathrm{p}}{ }^{2}=0.02$, and a significant interaction effect of analysis group and condition for the Error scores, $\mathrm{F}(4,612)=3.71, \mathrm{p}=0.005, \eta_{\mathrm{p}}{ }^{2}=0.02$ (Sup- plementary Table 4 in the online-only Data Supplement). Follow-up analyses showed that the TD group made significantly less errors in the Copy condition than in the IR and DR conditions ( $\mathrm{MD}=1.27$ and 1.25 , respectively), both $\mathrm{p}<0.05$, but the number of errors did not significantly differ across the three conditions in the ASD group (MD between Copy and IR, between Copy and DR, and between IR and DR $=0.40,0.32$, and 0.08 , respectively), all $\mathrm{p}>0.05$, and the sibling group (MD between Copy and IR, between Copy and DR, and between IR and $\mathrm{DR}=0.13,0.29$, and 0.17 , respectively), all $\mathrm{p}>0.05$.

The results of the ANCOVA analyses showed that the effects of condition were significant in Organization, $F(2,612)=$ 25.08, $\mathrm{p}<0.001, \eta_{\mathrm{p}}{ }^{2}=0.08$. Post-hoc Tukey-Kramer comparisons showed that scores of the Copy condition were significantly higher than those of the IR and $\mathrm{DR}$ conditions $(\mathrm{MD}=$ 1.21 and 1.06 , respectively), both $\mathrm{p}<0.05$, and there was no difference between the two recall conditions $(\mathrm{MD}=0.15)$ (Figure 6). There was no other main effect of the analysis group or interaction effects.

\section{Associations with autistic symptoms and ROCF scores}

A correlation matrix of all continuous variables is presented in Table 4. Correlational analyses showed that there were 
Table 3. Repeated measure ANCOVA results

\begin{tabular}{|c|c|c|c|c|c|c|c|}
\hline Parameter & Source & Sum of squares & $\mathrm{df}$ & Mean square & $\mathrm{F}$ & $\mathrm{p}$ & Partial eta-square \\
\hline \multirow[t]{8}{*}{ Organization } & Covariates & & & & & & \\
\hline & Age & 14.45 & 1 & 14.45 & 0.44 & 0.51 & $<0.01$ \\
\hline & Performance IQ & 20.44 & 1 & 20.44 & 0.62 & 0.43 & $<0.01$ \\
\hline & Diagnostic group & 146.25 & 2 & 73.12 & 2.22 & 0.11 & 0.01 \\
\hline & Condition & 336.54 & 2 & 168.27 & 25.08 & $<0.001$ & 0.08 \\
\hline & Diagnostic group $\mathrm{x}$ condition & 9.05 & 4 & 2.26 & 0.34 & 0.85 & $<0.01$ \\
\hline & Error & 4119.79 & 614 & 6.71 & & & \\
\hline & Total & 18139.98 & 954 & 19.01 & & & \\
\hline \multirow[t]{8}{*}{ Error } & Covariates & & & & & & \\
\hline & Age & 1.61 & 1 & 1.61 & 0.16 & $<0.001$ & $<0.01$ \\
\hline & Performance IQ & 0.01 & 1 & 0.01 & $<0.001$ & 0.98 & $<0.01$ \\
\hline & Diagnostic group & 77.76 & 2 & 38.88 & 3.87 & 0.02 & 0.02 \\
\hline & Condition & 89.40 & 2 & 44.70 & 19.15 & $<0.001$ & 0.06 \\
\hline & Diagnostic group $\mathrm{x}$ condition & 34.63 & 4 & 8.66 & 3.71 & 0.005 & 0.02 \\
\hline & Error & 1428.23 & 612 & 2.33 & & & \\
\hline & Total & 4909.93 & 951 & 5.16 & & & \\
\hline \multirow[t]{8}{*}{ Structural accuracy } & Covariates & & & & & & \\
\hline & Age & 13.59 & 1 & 13.59 & 0.16 & 0.69 & $<0.01$ \\
\hline & Performance IQ & 11.27 & 1 & 11.27 & 0.13 & 0.72 & $<0.01$ \\
\hline & Diagnostic group & 1151.02 & 2 & 575.51 & 6.59 & 0.002 & 0.04 \\
\hline & Condition & 5177.58 & 2 & 2588.79 & 121.61 & $<0.001$ & 0.28 \\
\hline & Diagnostic group $\mathrm{x}$ condition & 104.40 & 4 & 26.10 & 1.23 & 0.30 & 0.01 \\
\hline & Error & 13028.10 & 612 & 21.29 & & & \\
\hline & Total & 55993.51 & 952 & 58.82 & & & \\
\hline \multirow[t]{8}{*}{ Incidental accuracy } & Covariates & & & & & & \\
\hline & Age & 4.42 & 1 & 4.42 & 0.03 & 0.87 & $<0.01$ \\
\hline & Performance IQ & 10.48 & 1 & 10.48 & 0.06 & 0.80 & $<0.01$ \\
\hline & Diagnostic group & 4684.95 & 2 & 2342.48 & 14.23 & $<0.001$ & 0.08 \\
\hline & Condition & 36010.33 & 2 & 18005.17 & 486.44 & $<0.001$ & 0.61 \\
\hline & Diagnostic group $\mathrm{x}$ condition & 48.90 & 4 & 12.22 & 0.33 & 0.86 & $<0.01$ \\
\hline & Error & 22652.60 & 612 & 37.01 & & & \\
\hline & Total & 136073.38 & 952 & 142.93 & & & \\
\hline \multirow[t]{8}{*}{ Configurational style } & Covariates & & & & & & \\
\hline & Age & 1.14 & 1 & 1.14 & 2.81 & 0.09 & 0.01 \\
\hline & Performance IQ & 1.53 & 1 & 1.53 & 3.78 & 0.05 & 0.01 \\
\hline & Diagnostic group & 8.29 & 2 & 4.15 & 10.27 & $<0.001$ & 0.06 \\
\hline & Condition & 3.54 & 2 & 1.77 & 12.81 & $<0.001$ & 0.04 \\
\hline & Diagnostic group $\mathrm{x}$ condition & 1.62 & 4 & 0.40 & 2.93 & 0.02 & 0.02 \\
\hline & Error & 84.68 & 612 & 0.14 & & & \\
\hline & Total & 235.25 & 952 & 0.25 & & & \\
\hline \multirow[t]{8}{*}{ Part-oriented style } & Covariates & & & & & & \\
\hline & Age & 0.85 & 1 & 0.85 & 2.78 & 0.10 & $<0.01$ \\
\hline & Performance IQ & 0.70 & 1 & 0.70 & 2.31 & 0.13 & $<0.01$ \\
\hline & Diagnostic group & 10.02 & 2 & 5.01 & 16.40 & $<0.001$ & 0.09 \\
\hline & Condition & 0.07 & 2 & 0.04 & 0.39 & 0.68 & $<0.01$ \\
\hline & Diagnostic group $\mathrm{x}$ condition & 0.64 & 4 & 0.16 & 1.73 & 0.14 & 0.01 \\
\hline & Error & 56.45 & 612 & 0.09 & & & \\
\hline & Total & 173.45 & 952 & 0.18 & & & \\
\hline
\end{tabular}

df: degrees of freedom, IQ, intelligence quotients 


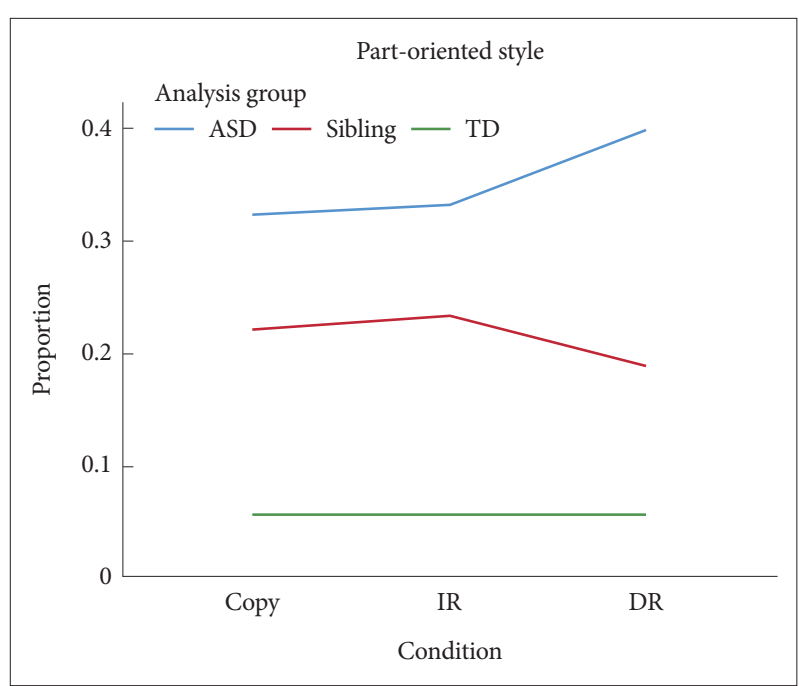

Figure 1. Proportions of participants who drew in a part-oriented style by diagnostic group and condition. ASD: autism spectrum disorder, TD: typically developing, IR: immediate recall, DR: delayed recall.

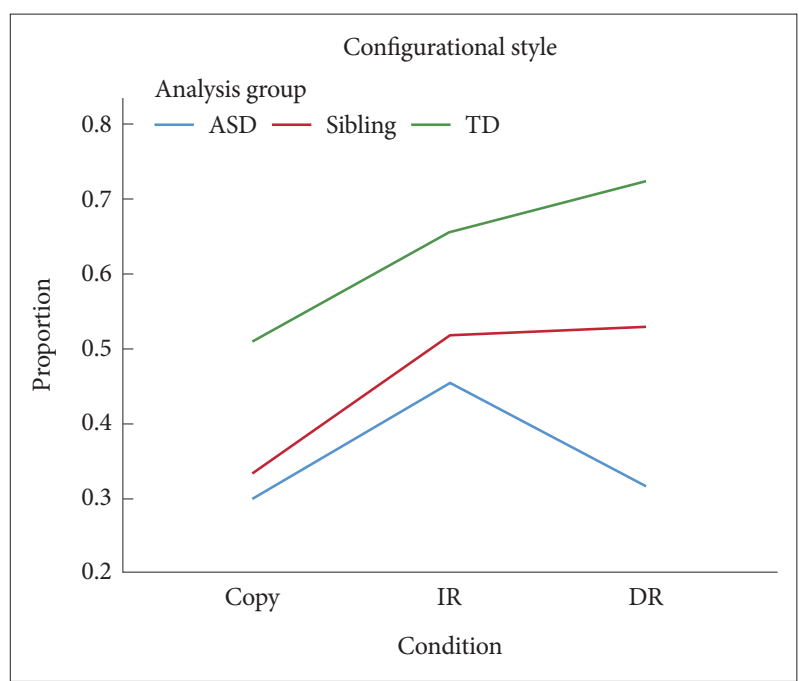

Figure 2. Proportions of participants who drew in a configurational style by diagnostic group and condition. ASD: autism spectrum disorder, TD: typically developing, IR: immediate recall, DR: delayed recall.

significant negative correlations between Social Interaction and Organization scores in Copy, $\mathrm{r}(140)=-0.258, \mathrm{p}=0.002$, controlling for the performance IQ. No significant correlation with the Verbal Communication domain was found, but a trend toward significance between Error in Delayed and Recall conditions and Verbal Communication emerged, $\mathrm{r}(112)=0.24, \mathrm{p}=$ 0.01 , and $\mathrm{r}(108)=0.21, \mathrm{p}=0.03$, respectively. However, this was not considered significant after applying Holm-Bonferroni correction. Regression analysis (Table 5) showed whether or not a child with ASD drew in the Part-Oriented style in the Copy condition significantly predicted his/her RRB scores, $\beta=0.25, p=0.006, R^{2}=0.06,95 \%$ confidence interval of $R^{2}(0.016$,

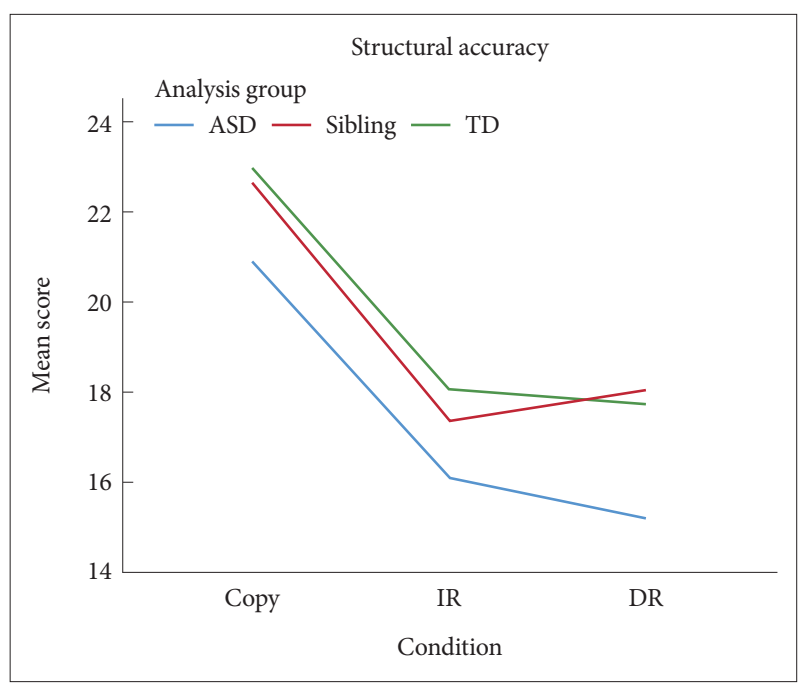

Figure 3. Mean structural accuracy scores by diagnostic group and condition. ASD: autism spectrum disorder, TD: typically developing, IR: immediate recall, DR: delayed recall.

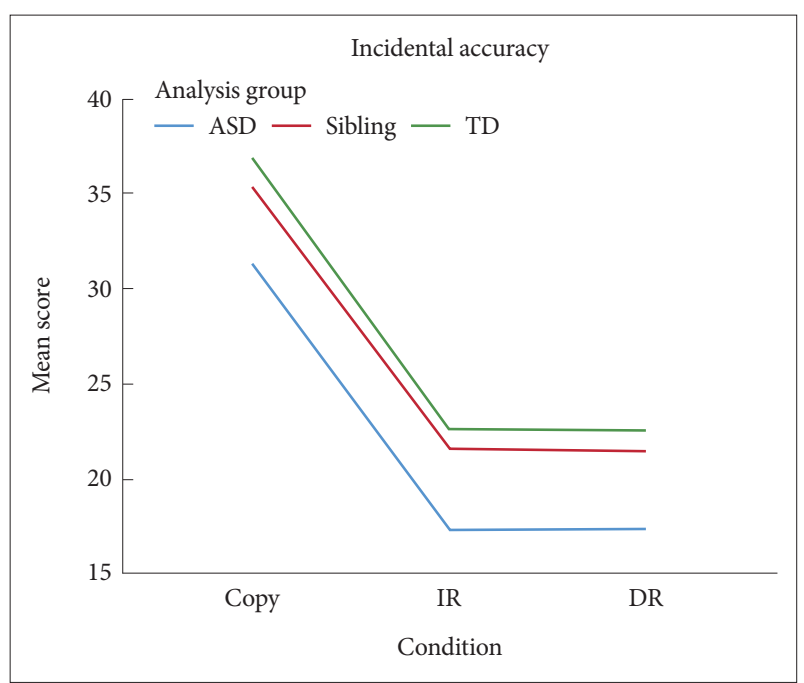

Figure 4. Mean incidental accuracy scores by diagnostic group and condition. ASD: autism spectrum disorder, TD: typically developing, IR: immediate recall, DR: delayed recall.

0.136). No significant association between the two Style variables and Social Interaction and Verbal Communication was reported (Supplementary Tables 5 and 6 in the online-only Data Supplement). Among the subdomains of RRBs, only drawing in a Part-Oriented style significantly predicted preoccupation with parts of objects or non-functional elements of material domain, $\beta=0.20, p=0.01, R^{2}=0.04,-0.02 \leq R^{2} \leq 0.11$.

\section{DISCUSSION}

Children with ASD, siblings of children with ASD, and TD children processed visuospatial stimuli differently as measured 
by some of the ROCF parameters. Although the ASD group performed similarly to the sibling and TD groups in the Organization parameter, they reproduced fewer items as measured by the Accuracy parameters than the TD and sibling groups. Moreover, unlike children with ASD who made a similar number of errors across the conditions, TD children made more errors during the Recall conditions compared to the Copy conditions. More children with ASD processed the visual information in a Part-Oriented style compared to siblings and TD children; more siblings processed the visual information in a Part-Oriented style compared to the TD children.

The Style variable provides information about encoding, storing, and recalling a visual image. ${ }^{18}$ The number of partici-

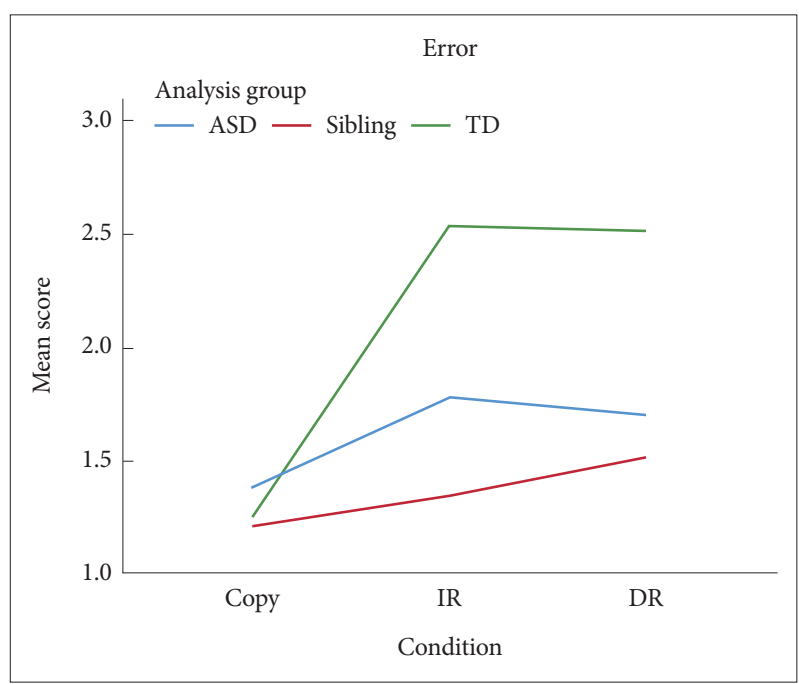

Figure 5. Mean error scores by diagnostic group and condition. ASD: autism spectrum disorder, TD: typically developing, IR: immediate recall, DR: delayed recall.

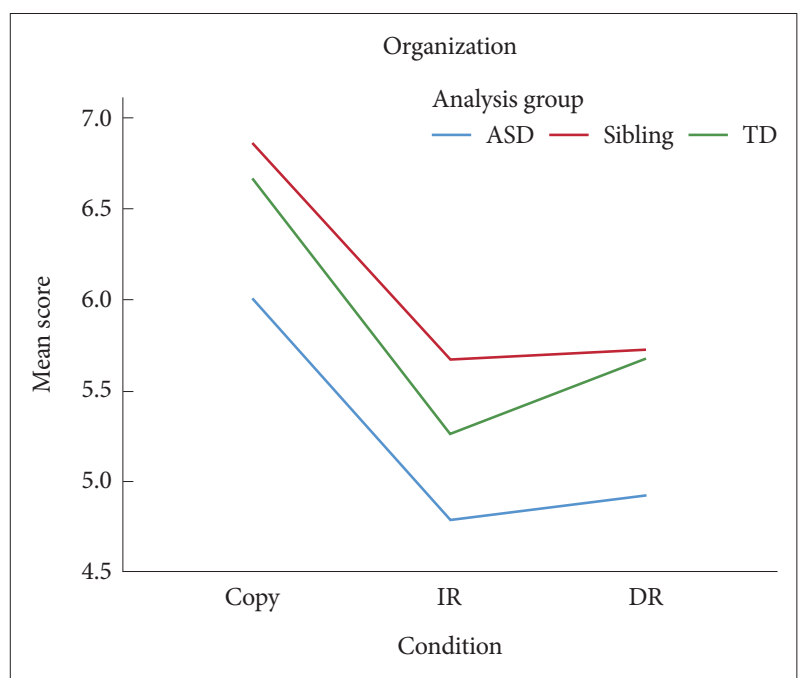

Figure 6. Mean organization scores by diagnostic group and condition. ASD: autism spectrum disorder, TD: typically developing, IR: immediate recall, DR: delayed recall. pants who drew in the Part-Oriented style did not differ across the two Recall conditions for all participants, suggesting that they maintained their style despite having the time to encode

Table 4. Partial correlation between autistic symptoms and organization, accuracy and error

\begin{tabular}{lccc}
\hline & $\begin{array}{c}\text { Social } \\
\text { interaction }\end{array}$ & $\begin{array}{c}\text { Verbal } \\
\text { communication }\end{array}$ & RRB \\
\hline Organization copy & $-0.25^{\dagger}$ & -0.15 & $-0.22^{*}$ \\
Organization IR & $-0.25^{*}$ & 0.05 & -0.17 \\
Organization DR & $-0.25^{*}$ & 0.01 & -0.16 \\
Structural accuracy copy & -0.08 & -0.14 & -0.10 \\
Structural accuracy IR & -0.16 & 0.02 & -0.15 \\
Structural accuracy DR & $-0.25^{*}$ & -0.10 & -0.16 \\
Incidental accuracy copy & -0.14 & -0.15 & -0.13 \\
Incidental accuracy IR & -0.16 & -0.04 & -0.14 \\
Incidental accuracy DR & $-0.23^{*}$ & -0.16 & -0.16 \\
Error copy & 0.04 & 0.11 & 0.05 \\
Error IR & 0.11 & $0.24^{*}$ & 0.13 \\
Error DR & 0.02 & $0.21^{*}$ & 0.02 \\
\hline
\end{tabular}

${ }^{*} \mathrm{p}<0.05$, ${ }^{\dagger}$ significant after Holm-Bonferroni correction. IR: immediate recall, DR: delayed recall, RRB: repetitive and restricted behavior

Table 5. Summary of regression analysis for predicting repetitive and restrictive behaviors with style variables

\begin{tabular}{crrrrr}
\hline Predictor & B & SE B & $\beta$ & $\mathrm{F}$ & $\mathrm{R}^{2}$ \\
\hline Configurational style & & & & & \\
Copy & & & & & \\
$\quad$ Configurational & -0.60 & 0.43 & -0.11 & 1.12 & 0.02 \\
Performance IQ & $<-0.01$ & $<0.01$ & -0.06 & & \\
Immediate recall & & & & & \\
Configurational & -0.97 & 0.46 & $-0.20^{*}$ & 3.40 & 0.06 \\
$\quad$ Performance IQ & -0.01 & $<0.01$ & -0.17 & & \\
Delayed recall & & & & & \\
Configurational & -0.62 & 0.48 & -0.12 & 1.80 & 0.03 \\
Performance IQ & -0.01 & $<0.01$ & -0.14 & & \\
Part-oriented style & & & & & \\
Copy & & & & & \\
Part-oriented & 1.33 & 0.48 & $0.25^{\dagger}$ & 4.09 & 0.06 \\
Performance IQ & $<-0.01$ & $<0.01$ & -0.03 & 0.06 & \\
Immediate recall & & & & & \\
Part-oriented & 1.11 & 0.50 & $0.21^{*}$ & 3.70 & 0.06 \\
Performance IQ & -0.01 & $<0.01$ & -0.11 & & \\
Delayed recall & & & & & \\
Part-oriented & 1.18 & 0.48 & $0.23^{*}$ & 3.85 & 0.07 \\
Performance IQ & $<-0.01$ & $<0.01$ & -0.10 & & \\
\hline
\end{tabular}

${ }^{*} \mathrm{p}<0.05,{ }^{\dagger}$ significant after Holm-Bonferroni correction. IQ: intelligence quotient 
and store the information. Meanwhile, the number of children who drew in the Configurational style significantly increased from the Copy to the IR conditions for all three analysis groups. Our findings mirror the findings of Akshoomoff and Stiles, ${ }^{42,43}$ which demonstrated that TD children tended to use more configurational styles in delayed conditions than in the Copy conditions. Moreover, this finding serves as evidence that many children with ASD and siblings used more Configurational styles at least in the IR condition than in the Copy condition, similar to the pattern observed in the TD children.

However, the number of children who drew in the Configurational style significantly decreased in the ASD group from the IR to the DR conditions, while remaining the same in the TD and sibling groups. One postulation is that the transition from the IR to the DR condition may be closely related to memory storage, defined as "the retention of briefly presented new information over a period of time in which the information is no longer present." ${ }^{\prime 4}$ Therefore, this finding suggests that some children with ASD changed from processing the visual stimuli in a Configurational way to storing and reproducing it in a Part-Oriented way over a period of 30 minutes. Studies are needed to unearth what cognitive factors could account for this evidenced shift in the visuospatial processing styles of some children with ASD between IR and DR conditions.

In the Style domains across all conditions, the proportion of participants who drew in a Part-Oriented style was highest in the ASD group, followed by siblings and then the TD group. In comparison, the number of participants who drew in the Configurational style was lowest in the ASD group and highest in the TD group. This pattern mirrors the findings of Tsatsanis et al. ${ }^{18}$ and supports our hypothesis that the highest number of children who drew a Part-Oriented processing style would be in the ASD group and followed in the order of the sibling group and then the TD group.

Because not all siblings and children with ASD are biologically related, drawing a strong conclusion may be limited. Identified differences among the ASD, TD, and sibling groups suggest that some siblings exhibit BAPs and provide evidence that local processing style is a possible cognitive endophenotype of ASD. However, Style variables represent the proportion rather than the extent to which participants who drew in the PartOriented or Configurational way. We urge future studies to replicate the current findings with a more continuous measure that can quantify Style as a fragmentation measure to fully understand the mechanism of local processing as an ASD endophenotype. ${ }^{18}$

Consistent with the hypothesis, children with ASD scored lower on the Structural and Incidental Accuracy parameters than siblings and TD children even when performance IQ was taken into account. It is possible that children with ASD only paid attention to and reproduced components of their interest, adding evidence to the local processing bias of ASD. It is noteworthy that there was no significant difference between the sibling and TD groups, indicating that the difference between the drawing styles of the two groups was not translated into sibling group's actual scores on Accuracy parameters.

In the Error parameter, both the ASD and the sibling groups had lower error scores than the TD group. A significant interaction effect also emerged in Error, in which the number of errors increased with time delay in the TD group, while it remained consistent across the conditions in the ASD and sibling groups. A possible explanation is that the children with ASD drew significantly fewer components than both the TD and the sibling groups, as reported in the Structural and Incidental Accuracy parameter. Hence, there may have been less opportunities for children with ASD to make errors. A second possible explanation is that children with ASD stored visual information in a piecemeal fashion by fixating on characteristics of specific components and, therefore, were able to accurately reproduce those components regardless of the delay in time. Also, the Sibling group showed significantly less error than the TD group, although the number of items drawn did not differ. The TD and Sibling groups had a comparable ability to copy and reproduce a similar number of components as evidenced by statistically insignificant differences in Accuracy scores. We suggest that the Sibling group, which had significantly more participants who drew in a Part-Oriented way than the TD group, may have had the advantage of focusing on details and reproducing the components with less error than the TD group.

Similar to the findings of Tsatsanis et al. ${ }^{18}$ and contrary to our hypothesis, children with ASD did not show difficulties with Organization than the TD and Sibling groups. The Organization scores assess how a child generally perceives and understands the basic structure of the figure. ${ }^{14}$ Hence, the Accuracy and Error parameters depend on what components the child chooses to reproduce. The findings here suggest that the children with ASD may have had intact meta-cognitive ability to organize the stimuli but preferred to focus on and reproduce the components in which they were particularly interested. Baron-Cohen and Belmonte ${ }^{45}$ also argue that despite differences in the process by which they achieve global organization of incoming stimuli, individuals with ASD do have the ability to understand global relationships.

The second purpose of the study was to examine whether autistic behaviors are associated with the cognitive profiles produced by the ROCF. Two significant associations between Social Interaction and Organization in the Copy condition and between Part-Oriented style and RRBs remained after application of Holms-Bonferroni correction. 
A significant association between the Organization in Copy condition and Social Interaction scores suggests the possibility of a shared mechanism in the tendency to perceive and organize a complex visual stimulus as parts rather than an integrated figure and difficulties in understanding various social stimuli encountered in real-life settings. Consistent with Brunsdon and Happe's theory, ${ }^{23}$ because individuals with ASD prefer attending to each social stimulus without integrating it with others, it may not be natural for them to read the holistic context of social interaction when not explicitly asked to do so. Deruelle et al. ${ }^{46}$ and colleagues also demonstrated that children with ASD relied more on local than configurational cues when visually processing faces, while the opposite pattern was identified in the TD group. Nevertheless, it should be emphasized that a tendency to see parts most likely does not discretely explain all aspects of the social interaction difficulties of individuals with ASD. Instead, the findings of this study highlight the need to investigate how individuals with ASD perceive and integrate discrete visual social stimuli and how it influences their social interaction.

The predilection of a child with ASD to draw in a Part-Oriented style in the Copy condition was significantly associated with RRBs, particularly in preoccupation with parts of objects or non-functional elements. This could be because some children with ASD are more interested in parts of an object due to their tendency to spend more of their cognitive resources on exploring specific parts rather than trying to come up with the whole picture. The current findings construct a link between performance on cognitive tasks and everyday behavioral symptoms, which Pellicano et al. ${ }^{26}$ identified as a key challenge for future researchers.

However, the $\mathrm{R}^{2}$ values of the regression models were not significantly different from 0 , questioning the practical interpretation of the identified significant association. It is also important to note that the preoccupation with parts of objects or nonfunctional elements variable consisted of only one item. This warrants the need for more studies investigating what covariates can be included to increase the true explanatory power of these regression models and how changes in autistic behaviors are translated into changes in performance on cognitive tasks.

Finally, although the associations between verbal communication and autistic symptoms were not significant after applying the Holm-Bonferroni correction, the findings suggested a trend that Error scores in both Recall conditions were associated with verbal communication. This is in line with the theory of Noens and Berckelaer-Onnes ${ }^{47}$ which stated that language and communicative ability requires comprehension and use of symbols in a variety of contexts. Yet, the local processing bias of ASD may make it optional for an individual with ASD to decontextualize symbols from previously experienced con- texts or form associations between the symbol and the new context, resulting in increased usage of gestalt style verbal communication. Therefore, future researchers should not dismiss this finding and examine the association between Verbal Communication and Error scores in the Recall conditions with a more specific set of hypotheses.

\section{Implications}

These findings suggest avenues for future research and practical implications. First, the performance of children with ASD did not uniformly differ from those of the TD and Sibling groups across all parameters. To our knowledge, there was no literature explicating what cognitive procedures are distinctively captured by each parameter. Eylen et al. ${ }^{22}$ contend that local processing is not a well-defined or established construct in ASD literature despite the numerous theories that attempt to utilize local processing theory to account for autistic behaviors. More research on the underlying cognitive mechanisms of local processing styles and how they manifest in the different parameters of the ROCF tasks is needed to better understand why such nuanced patterns were observed in the current study and apply the findings to clinical use. Additionally, we suggest incorporating the ROCF task with neuroimaging studies and short time scale studies to draw a more direct conclusion about how individuals with ASD perceive and process visuospatial stimuli.

Furthermore, we want to emphasize that, consistent with Frith's argument, ${ }^{1}$ this particular processing style is not a deficit but rather a trait that can explain many strengths and/or savant skills of individuals with ASD. The tendency of children with ASD to make sense of complex stimuli by parsing it into its parts bears educational implications in terms of how to format educational materials and environments to effectively support them. For instance, rather than expecting children with ASD to make sense of materials using top-down processes (i.e., identify the big picture and attend to the components based on the understanding of the big picture), it would be more helpful to present the information in small units and support them in the process of referencing the whole picture.

This study supports the claim that the altered pattern of visuospatial processing is an inherent trait of ASD by reporting that siblings of children with ASD showed BAP, a processing style that resembles that of children with ASD. However, it is also interesting to note that their processing style did not negatively impact their ability to organize the information or reproduce the components. Indeed, when their collective scores in Accuracy and Error parameters are considered, the siblings' performance was superior to those of both the TD and ASD groups in that they were able to reproduce as many figures as TD children did, but they had the least number of errors. Re- 
latedly, Pring et al. ${ }^{48}$ also contend that the tendency toward segmentation of visual information may account for artistic talents and aptitude for drawing even for TD children. This finding suggests the possibility of an endophenotype of ASD that prefers local processing to be considered a strength.

\section{Limitations}

This study has several limitations to be considered. First, the generalization of the findings may be limited as only children with sufficient motor or cognitive skills to perform the ROCF tasks were included. Also, to maintain the accuracy of the DSS scores, the analysis was restricted to children under the age of 15. However, the influence of maturation and age on changes in processing style has been articulated in previous studies. ${ }^{18,22}$ This limitation warrants the need to develop a new instrument that can be applied across various age groups to accurately measure visuospatial processing patterns. It is also important to note that the results are drawn from a single visuospatial task. We, therefore, suggest that future studies with additional visual-processing tasks such as a block-design task are needed to triangulate the findings of this study.

The number of participants and percentages of males in the ASD, sibling, and TD group were imbalanced. As gender is an important predictor of processing style, ${ }^{22}$ replication studies with balanced demographic groups are needed to confirm the findings of the study. Furthermore, it is important to note that the TD children were not longitudinally tracked, and therefore does not rule out the possibility of transitioning into the sibling group in the future. The groups were not matched on verbal IQ although previous studies on TD children showed that verbal IQ was a determining factor in the accurate reproduction of visual stimuli. ${ }^{31,49}$ Relatedly, the low Accuracy scores of the ASD group may reflect low working memory skills rather than their visuospatial processing abilities. It is possible that individual characteristics such as verbal IQ, memory skills, or autism severity may have accounted for the differences between the groups. Therefore, the current study needs to be replicated with consideration of participants' individual factors that may influence the performance on the ROCF tasks.

Finally, although Holm-Bonferroni corrections, a procedure with progressively adaptive threshold values ${ }^{50}$ are considered more powerful than Bonferroni corrections by lowering the risk of increased type II error (i.e., not rejecting the null hypothesis when an alternative hypothesis is true), application of HolmBonferroni corrections may still have inflated the possibility of Type II error.

\section{Supplementary Materials}

The online-only Data Supplement is available with this article at https://doi.org/10.30773/pi.2020.0189.

\section{Acknowledgments}

This work was supported by Institute of Information \& Communications Technology Planning \& Evaluation (IITP) grant funded by the Korea government (MSIT) (2019-0-00330) and Original Technology Research Program for Brain Science of NRF funded by the Korean government (MSIT) (NRF-2017M3C7A1027467).

\section{Conflicts of Interest}

The authors have no potential conflicts of interest to disclose.

\section{Author Contributions}

Conceptualization: So Yoon Kim, Hee Jeong Yoo. Data curation: So Yoon Kim, Guiyoung Bong. Formal analysis: So Yoon Kim. Funding acquisition: Hee Jeong Yoo. Investigation: So Yoon Kim. Methodology: So Yoon Kim. Project administration: Guiyoung Bong, Joo Hyun Kim. Supervision: Hee Jeong Yoo. Writing — original draft: So Yoon Kim, Da-Yea Song, Young Ah Kim. Writing_review \& editing: So Yoon Kim, Da-Yea Song, Young Ah Kim, Jong Myeong Kim, Joo Hyun Kim, Hee Jeong Yoo.

\section{ORCID iDs}

So Yoon Kim Da-Yea Song Young Ah Kim Guiyoung Bong Jong-myeong Kim Joo Hyun Kim Hee Jeong Yoo

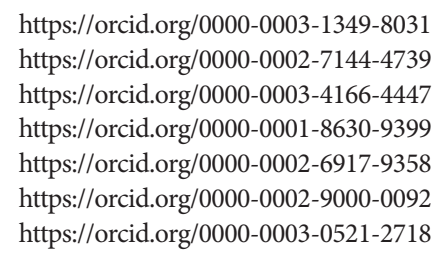
https://orcid.org/0000-0002-7144-4739 https://orcid.org/0000-0003-4166-4447 https://orcid.org/0000-0001-8630-9399 https://orcid.org/0000-0002-6917-9358 https://orcid.org/0000-0002-9000-0092 https://orcid.org/0000-0003-0521-2718

\section{REFERENCES}

1. Frith U. Autism: Explaining the Enigma. Oxford: Blackwell; 1989.

2. Shah A, Frith U. An islet of ability in autism: a research note. J Child Psychol Psychiatry 1983;24:613-620.

3. Happe F, Booth R. The power of the positive: revisiting weak coherence in autism spectrum disorders. Q J Exp Psychol 2008;61:50-63.

4. Booth R. Local-Global Processing and Cognitive Style in Autism Spectrum Disorder and Typical Development. London: Unpublished PhD thesis, King's College London; 2006.

5. Mottron L, Dawson M, Soulières I, Hubert B, Burack J. Enhanced perceptual functioning in autism: an update, and eight principles of autistic perception. J Autism Dev Disord 2006;36:27-43.

6. Spencer MD, Holt RJ, Chura LR, Calder AJ, Suckling J, Bullmore ET, et al. Atypical activation during the Embedded Figures Task as a functional magnetic resonance imaging endophenotype of autism. Brain 2012;135:3469-3480.

7. Barnea-Goraly N, Lotspeich LJ, Reiss AL. Similar white matter aberrations in children with autism and their unaffected siblings: a diffusion tensor imaging study using tract-based spatial statistics. Arch Gen Psychiatry 2010;67:1052-1060.

8. Billeci L, Calderoni S, Conti E, Gesi C, Carmassi C, Dell'Osso L, et al. The broad autism (endo)phenotype: neurostructural and neurofunctional correlates in parents of individuals with autism spectrum disorders. Front Neurosci 2016;10:346.

9. Behrmann M, Thomas C, Humphreys K. Seeing it differently: visual processing in autism. Trends Cogn Sci 2006;10:258-264.

10. Simmons DR, Robertson AE, McKay LS, Toal E, McAleer P, Pollick FE. Vision in autism spectrum disorders. Vision Res 2009;49:2705-2739.

11. Van der Hallen R, Evers K, Brewaeys K, Van den Noortgate W, Wagemans J. Global processing takes time: a meta-analysis on local-global visual processing in ASD. Psychol Bull 2015;141:549-573.

12. Rey A. L'examen psychologique dan les cas d'encephalo- pathie traumatique. [Psychological examination of traumatic encephalopathy]. Arch Psychol (Geneve) 1941;23:286-340.

13. Osterrieth PA. Le test de copie d'une figure complexe. Contribution à 
létude de la perception et de la mémoire [The copy of a complex figure test]. Arch Psychol (Geneve) 1944;28:286-340.

14. Bernstein JH, Waber DP. Developmental Scoring System for the ReyOsterrieth Figure. Professional Manual. Lutz, FL: Psychological Assessment Resources, Inc; 1996.

15. Schlooz WAJM, Hulstijn W, van den Broek PJA, van der Pijll ACAM, Gabreëls F, van der Gaag RJ, et al. Fragmented visuospatial processing in children with pervasive developmental disorder. J Autism Dev Disord 2006;36:1025-1037.

16. Gunter $\mathrm{H}$, Ghaziuddin M, Ellis $\mathrm{H}$. Asperger syndrome: tests of right hemisphere functioning and interhemispheric communication. J Autism Dev Disord 2002;32:263-281.

17. Jolliffe T, Baron-Cohen S. Are people with autism and Asperger syndrome faster than normal on the embedded figures test? J Child Psychol Psychiatry 1997;38:527-534.

18. Tsatsanis KD, Noens ILJ, Illmann CL, Pauls DL, Volkmar FR, Schultz RT, et al. Managing complexity: impact of organization and processing style on nonverbal memory in autism spectrum disorders. J Autism Dev Disord 2011;41:135-147.

19. Minshew NJ, Goldstein G. The pattern of intact and impaired memory functions in autism. J Child Psychol Psychiatry 2001;42:1095-1101.

20. Prior M, Hoffmann W. Brief report: neuropsychological testing of autistic children through an exploration with frontal lobe tests. J Autism Dev Disord 1990;20:581-590.

21. Kuschner E, Bodner K, Minshew N. Local vs. global approaches to reproducing the Rey Osterrieth Complex Figure by children, adolescents, and adults with high-functioning autism. Autism Res 2009;2:348-358.

22. Eylen LV, Boets B, Steyaert J, Wagemans J, Noens I. Local and global visual processing in autism spectrum disorders: influence of task and sample characteristics and relation to symptom severity. J Autism Dev Disord 2015;48:1359-1381.

23. Brunsdon V, Happe F. Exploring the 'fractionation' of autism at the cognitive level. Autism 2013;18:17-30.

24. Russell-Smith SN, Maybery MT, Bayliss DM, Sng AAH. Support for a link between the local processing bias and social deficits in autism: an investigation of embedded figures test performance in non-clinical individuals. J Autism Dev Disord 2012;42:2420-2430.

25. Burnette C, Mundy P, Meyer J, Sutton S, Van Hecke A, Charak D. Weak central coherence and its relations to theory of mind and anxiety in autism. J Autism Dev Disord 2005;35:63-73.

26. Pellicano E, Maybery M, Durkin K, Maley A. Multiple cognitive capabilities/deficits in children with an autism spectrum disorder: "weak" central coherence and its relationship to theory of mind and executive control. Dev Psychopathol 2006;18:77-98.

27. Noens I, Berckelaer-Onnes I. Captured by details: sense-making, language and communication in autism. J Commun Disord 2005;38:123141.

28. Prizant B. Language acquisition and communicative behavior in autism: Toward an understanding of the 'whole' of it. J Speech Hear Disord 1983;48:296-307.

29. Rutter M, A LC, Lord C. Autism Diagnostic Interview-Revised. Los Angeles, CA: Western Psychological Services; 2003.

30. Chen Y-H, Rodgers J, McConachie H. Restricted and repetitive behaviours, sensory processing and cognitive style in children with autism spectrum disorders. J Autism Dev Disord 2008;39:635-642.

31. Drake J, Redash A, Coleman K, Haimson J, Winner E. 'Autistic' local processing bias also found in children gifted in realistic drawing. J Autism Dev Disord 2010;40:762-773.

32. Lord S, Rutter M, DiLavore PC, Risi S. Autism Diagnostic Observation Schedule. Los Angeles, CA: Western Psychological Services; 2001.

33. Lord C, Luyster R, Gotham K, Guthrie W. Autism Diagnostic Observation sSchedule, Second Edition (ADOS-2) Manual. Torrance, CA: Western Psychological Services; 2012.

34. Yoo H, Bong G, Kwak Y, Lee M, Cho S, Kim B, et al. Korean Version of Autism Diagnostic Observation Schedule-Second Edition (ADOS-2). Seoul: Inpsyt; 2017.

35. Yoo H, Park K, Kwak Y, Cho S, Ban G, Kim B. Korean Version of Autism Diagnostic Interview-Revised (ADI- R). Seoul: Inpsyt; 2007.

36. Constantino JN, Gruber CP. Social Responsiveness Scale-Second Edition (SRS-2). Torrance, CA: Western Psychological Services.; 2012.

37. Roid GH, Miller LJ. The Leiter International Performance Scale-Revised Edition. Wood Dale, IL: Stoelting; 1997.

38. Bong G, Kim JH, Hong Y, Yoon NH, Sunwoo H, Jang J, et al. The feasibility and validity of autism spectrum disorder screening instrument: behavior development screening for toddlers (BeDevel)_A pilot study. Autism Res 2019;12:1112-1128.

39. Shin M, Cho S. Korean Leiter International Performance Scale Revised (K-Leiter-R). Seoul: Hakjisa; 2010.

40. Shah A, Holmes N. Brief report: the use of the Leiter International Performance Scale with autistic children. J Autism Dev Disord 1985; 15:195-203.

41. StataCorp. Stata Statistical Software: Release 15. College Station, TX: StataCorp LLC; 2017.

42. Akshoomoff N, Stiles J. Developmental trends in visuospatial analysis and planning: I. Copying a complex figure. Neuropsychology 1995;9: 364-377.

43. Akshoomoff N, Stiles J. Developmental trends in visuospatial analysis and planning: II. memory for a complex figure. Neuropsychology 1995; 9:378-389.

44. Oberauer K, Süß H-M, Wilhelm O, Wittmann W. The multiple faces of working memory: Storage, processing, supervision, and coordination. Intelligence 2003;31:167-193.

45. Baron-Cohen S, Belmonte M. Autism: a window onto the development of the social and the analytic brain. Annu Rev Neurosci 2005;28:109126.

46. Deruelle C, Rondan C, Gepner B, Tardif C. Spatial frequency and face processing in children with autism and asperger syndrome. J Autism Dev Disord 2004;34:199-210.

47. Noens I, van Berckelaer-Onnes I. Making sense in a fragmentary world: communication in people with autism and learning disability. Autism 2004;8:197-218.

48. Pring L, Hermelin B, Heavey L. Savants, segments, art and autism. J Child Psychol Psychiatry 1995;36:1065-1076.

49. Oconnor N, Hermelin B. Visual and graphic abilities of the idiot savant artist. Psychol Med 1987;17:79-90.

50. Holm S. A Simple sequentially rejective multiple test procedure. Scand J Stat 1979;6:65-70. 


\begin{tabular}{|c|c|c|}
\hline Parameter & Definition & Scoring method \\
\hline Organization & $\begin{array}{l}\text { Whether the individual sees } \\
\text { parts of the figure integrated } \\
\text { and connected }\end{array}$ & $\begin{array}{l}\text { The score is based on the number of accurately drawn critical features out of the } 24 \text { criterial } \\
\text { features of the figure (i.e., the accuracy of alignments and intersections of lines). The features } \\
\text { are weighted in a scale ranging from } 1 \text { being poorly organized to } 13 \text { being highly organized. } \\
\text { Line quality and drawing precision are measured separately from the figural organization to } \\
\text { prevent poor motor control from influencing the results. }\end{array}$ \\
\hline Style & $\begin{array}{l}\text { Whether an individual } \\
\text { processes the figure in part } \\
\text { or in gestalt }\end{array}$ & $\begin{array}{l}\text { The accuracy of the alignment of lines and the continuity (i.e., drawing using a single stroke) } \\
\text { of the lines constituting the base rectangle and the main intersecting lines within is used } \\
\text { to categorize the style into four categorical rating in Copy conditions (i.e., Part-oriented, } \\
\text { Outer Configurational/Inner Parts (OC/IP), Outer Part/Inner Configurational (OP/IC), } \\
\text { and Configurational) and three categorical rating in Recall conditions (i.e., configurational, } \\
\text { intermediate or part-oriented). As more lines are accurately aligned and continuously } \\
\text { drawn, the style is considered more configurational. Intermediate style has two } \\
\text { sub-categories in the copy condition only, which are outer configurational/inner part and } \\
\text { outer part/inner configurational. }\end{array}$ \\
\hline Accuracy & $\begin{array}{l}\text { How many elements of the } \\
\text { figure are present }\end{array}$ & $\begin{array}{l}\text { Structural: the total number of elements present out of the } 25 \text { structural elements such as } \\
\text { the base rectangle and the main lines of the structure. } \\
\text { Incidental: the total number of elements present out of the } 39 \text { incidental elements such as } \\
\text { structures outside and details inside the rectangle }\end{array}$ \\
\hline Error & $\begin{array}{l}\text { How many elements of the } \\
\text { figure are drawn inaccurately }\end{array}$ & $\begin{array}{l}\text { There are four types of error that can occur: rotation, perseveration, misplacement and } \\
\text { conflation. Rotation error is defined as more than } 45^{\circ} \text { rotation in lines, elements or the } \\
\text { whole figure. Perseveration error is a repetition of lines or elements. Misplacement error is } \\
\text { when an element is drawn in a wrong part of the structure. Conflation error occurs when a } \\
\text { single line is used as a part of two or more elements. Error score is calculated by adding the } \\
\text { number of total errors }\end{array}$ \\
\hline
\end{tabular}


Supplementary Table 2. Tukey-Kramer pairwise comparisons for condition

\begin{tabular}{|c|c|c|c|c|c|}
\hline \multirow{2}{*}{$\begin{array}{l}\text { Parameter } \\
\text { Organization }\end{array}$} & \multirow{2}{*}{$\begin{array}{c}\text { Condition } \\
\text { Copy vs. immediate recall }\end{array}$} & \multicolumn{2}{|c|}{ Group means } & \multirow{2}{*}{$\begin{array}{c}\text { Mean difference } \\
1.21\end{array}$} & \multirow{2}{*}{$\frac{\text { Tukey-Kramer test }}{8.44^{*}}$} \\
\hline & & 6.48 & 5.27 & & \\
\hline & Copy vs. delayed recall & 6.48 & 5.42 & 3.54 & $7.35^{*}$ \\
\hline & Immediate recall vs. delayed recall & 5.27 & 5.42 & 1.62 & 1.02 \\
\hline \multirow[t]{3}{*}{ Error } & Copy vs. immediate recall & 1.28 & 1.70 & 0.42 & $4.97^{*}$ \\
\hline & Copy vs. delayed recall & 1.28 & 1.74 & 0.46 & $5.45^{*}$ \\
\hline & Immediate recall vs. delayed recall & 1.70 & 1.74 & 0.04 & 0.51 \\
\hline \multirow[t]{3}{*}{ Structural accuracy } & Copy vs. immediate recall & 21.96 & 17.01 & 4.96 & $19.44^{*}$ \\
\hline & Copy vs. delayed recall & 21.96 & 16.94 & 5.02 & $19.56^{*}$ \\
\hline & Immediate recall vs. delayed recall & 17.01 & 16.94 & 0.06 & 0.25 \\
\hline \multirow[t]{3}{*}{ Incidental accuracy } & Copy vs. immediate recall & 33.76 & 20.15 & 13.61 & $40.48^{*}$ \\
\hline & Copy vs. delayed recall & 33.76 & 20.12 & 13.63 & $40.28^{*}$ \\
\hline & Immediate recall vs. delayed recall & 20.15 & 20.12 & 0.03 & 0.07 \\
\hline \multirow[t]{3}{*}{ Configurational } & Copy vs. immediate recall & 0.35 & 0.52 & 0.17 & $8.23^{*}$ \\
\hline & Copy vs. delayed recall & 0.35 & 0.49 & 0.14 & $6.64^{*}$ \\
\hline & Immediate recall vs. delayed recall & 0.52 & 0.49 & 0.03 & 1.52 \\
\hline
\end{tabular}

*significance calculated based on Tukey-Kramer-test value 3.22. Studentized range critical value $0.05,3,612$ 
Supplementary Table 3. Tukey-Kramer pairwise comparisons for analysis group

\begin{tabular}{|c|c|c|c|c|c|}
\hline \multirow{2}{*}{$\begin{array}{l}\text { Parameter } \\
\text { Error }\end{array}$} & \multirow{2}{*}{$\begin{array}{c}\text { Condition } \\
\text { ASD vs. sibling }\end{array}$} & \multicolumn{2}{|c|}{ Group means } & \multirow{2}{*}{$\begin{array}{c}\text { Mean difference } \\
0.25\end{array}$} & \multirow{2}{*}{$\frac{\text { Tukey-Kramer test }}{3.26}$} \\
\hline & & 1.60 & 1.35 & & \\
\hline & ASD vs. TD & 1.60 & 2.09 & 0.49 & $4.81^{*}$ \\
\hline & Sibling vs. TD & 1.35 & 2.09 & 0.74 & $7.49^{*}$ \\
\hline \multirow[t]{3}{*}{ Structural accuracy } & ASD vs. sibling & 17.58 & 19.35 & 1.77 & $7.64^{*}$ \\
\hline & ASD vs. TD & 17.58 & 19.56 & 1.98 & $6.44^{*}$ \\
\hline & Sibling vs. TD & 19.35 & 19.56 & 0.21 & 0.70 \\
\hline \multirow[t]{3}{*}{ Incidental accuracy } & ASD vs. sibling & 22.42 & 26.08 & 3.66 & $11.99^{*}$ \\
\hline & ASD vs. TD & 22.42 & 27.28 & 4.86 & $11.99^{*}$ \\
\hline & Sibling vs. TD & 26.08 & 27.28 & 1.20 & 3.04 \\
\hline \multirow[t]{3}{*}{ Configurational } & ASD vs. sibling & 0.35 & 0.46 & 0.11 & $5.63^{*}$ \\
\hline & ASD vs. TD & 0.35 & 0.63 & 0.28 & $11.11^{*}$ \\
\hline & Sibling vs. TD & 0.46 & 0.63 & 0.17 & $7.07^{*}$ \\
\hline \multirow[t]{3}{*}{ Part-Oriented } & ASD vs. sibling & 0.35 & 0.21 & 0.13 & $8.79 *$ \\
\hline & ASD vs. TD & 0.35 & 0.05 & 0.29 & $14.45^{*}$ \\
\hline & Sibling vs. TD & 0.21 & 0.05 & 0.16 & $8.06^{*}$ \\
\hline
\end{tabular}

*studentized range critical value $>3.22$. ASD: autism spectrum disorder, TD: typically developing 
Supplementary Table 4. Tukey-Kramer pairwise comparisons for interaction effects

\begin{tabular}{|c|c|c|c|c|c|c|}
\hline \multirow{2}{*}{$\begin{array}{l}\text { Parameter } \\
\text { Error }\end{array}$} & \multirow{2}{*}{$\frac{\text { Analysis group }}{\text { ASD }}$} & \multirow{2}{*}{$\begin{array}{c}\text { Condition } \\
\text { Copy vs. immediate recall }\end{array}$} & \multicolumn{2}{|c|}{ Group means } & \multirow{2}{*}{$\frac{\text { Mean difference }}{0.39}$} & \multirow{2}{*}{$\frac{\text { Tukey-Kramer tes }}{2.89}$} \\
\hline & & & 1.38 & 1.77 & & \\
\hline & & Copy vs. delayed recall & 1.38 & 1.69 & 0.32 & 2.29 \\
\hline & & Immediate recall vs. delayed recall & 1.77 & 1.69 & 0.08 & 0.56 \\
\hline & Sibling & Copy vs. immediate recall & 1.21 & 1.34 & 0.13 & 1.01 \\
\hline & & Copy vs. delayed recall & 1.21 & 1.51 & 0.29 & 2.33 \\
\hline & & Immediate recall vs. delayed recall & 1.34 & 1.51 & 0.17 & 1.32 \\
\hline & $\mathrm{TD}$ & Copy vs. immediate recall & 1.25 & 2.53 & 1.27 & $6.18^{*}$ \\
\hline & & Copy vs. delayed recall & 1.25 & 2.50 & 1.25 & $6.02 *$ \\
\hline & & Immediate recall vs. delayed recall & 2.53 & 2.50 & 0.03 & 0.13 \\
\hline \multirow[t]{9}{*}{ Configurational } & ASD & Copy vs. immediate recall & 0.30 & 0.45 & 0.15 & $4.60^{*}$ \\
\hline & & Copy vs. delayed recall & 0.30 & 0.32 & 0.02 & 0.50 \\
\hline & & Immediate recall vs. delayed recall & 0.45 & 0.32 & 0.14 & $3.91^{*}$ \\
\hline & Sibling & Copy vs. immediate recall & 0.33 & 0.52 & 0.18 & $6.02 *$ \\
\hline & & Copy vs. delayed recall & 0.33 & 0.53 & 0.19 & $6.34^{*}$ \\
\hline & & Immediate recall vs. delayed recall & 0.52 & 0.53 & 0.01 & 0.35 \\
\hline & TD & Copy vs. delayed recall & 0.51 & 0.65 & 0.15 & 2.90 \\
\hline & & Immediate recall vs. delayed recall & 0.51 & 0.72 & 0.21 & $4.23^{*}$ \\
\hline & & Immediate recall vs. delayed recall & 0.65 & 0.72 & 0.07 & 1.34 \\
\hline
\end{tabular}

*studentized range critical value $>3.22$. ASD: autism spectrum disorder, TD: typically developing 
Supplementary Table 5. Summary of regression analyses for predicting social interaction

\begin{tabular}{|c|c|c|c|c|c|}
\hline Predictor & $\mathrm{B}$ & SE B & $\beta$ & $\mathrm{F}$ & $\mathrm{R}^{2}$ \\
\hline \multicolumn{6}{|l|}{ Configurational style } \\
\hline \multicolumn{6}{|l|}{ Copy } \\
\hline Configurational & -1.24 & 0.93 & -0.11 & 1.07 & 0.01 \\
\hline Performance IQ & 0.01 & 0.01 & 0.06 & & \\
\hline \multicolumn{6}{|l|}{ Immediate recall } \\
\hline Configurational & -0.83 & 1.01 & -0.08 & 0.37 & 0.01 \\
\hline Performance IQ & $<0.01$ & 0.01 & 0.02 & & \\
\hline \multicolumn{6}{|l|}{ Delayed recall } \\
\hline Configurational & -1.83 & 1.04 & -0.16 & 1.55 & 0.03 \\
\hline Performance IQ & $<-0.01$ & 0.01 & $<-0.01$ & & \\
\hline \multicolumn{6}{|l|}{ Part-oriented style } \\
\hline \multicolumn{6}{|l|}{ Copy } \\
\hline Part-oriented & 0.18 & 1.00 & 0.02 & 0.19 & 0.002 \\
\hline Performance IQ & 0.01 & 0.01 & & & \\
\hline \multicolumn{6}{|l|}{ Immediate recall } \\
\hline Part-oriented & 0.92 & 1.11 & 0.08 & 0.37 & 0.01 \\
\hline Performance IQ & $<0.01$ & 0.01 & 0.04 & & \\
\hline \multicolumn{6}{|l|}{ Delayed recall } \\
\hline Part-oriented & 2.43 & 1.06 & $0.23^{*}$ & 2.61 & 0.05 \\
\hline Performance IQ & $<0.01$ & 0.01 & 0.03 & & \\
\hline
\end{tabular}

No significant association after applying Holm-Bonferroni correction. ${ }^{*} \mathrm{p}<0.05$. IQ: intelligent quotient 
Supplementary Table 6. Summary of regression analyses for predicting verbal communication

\begin{tabular}{|c|c|c|c|c|c|}
\hline Predictor & $\mathrm{B}$ & SE B & $\beta$ & $\mathrm{F}$ & $\mathrm{R}^{2}$ \\
\hline \multicolumn{6}{|l|}{ Configurational style } \\
\hline \multicolumn{6}{|l|}{ Copy } \\
\hline Configurational & -0.44 & 0.40 & -0.10 & 0.69 & 0.01 \\
\hline Performance IQ & $<-0.01$ & 0.003 & -0.01 & & \\
\hline \multicolumn{6}{|l|}{ Immediate recall } \\
\hline Configurational & -0.56 & 0.38 & -0.14 & 1.26 & 0.02 \\
\hline Performance IQ & $<-0.01$ & 0.003 & -0.07 & & \\
\hline \multicolumn{6}{|l|}{ Delayed recall } \\
\hline Configurational & -0.09 & 0.40 & -0.02 & 0.71 & 0.01 \\
\hline Performance IQ & $<-0.01$ & $<0.01$ & -0.08 & & \\
\hline \multicolumn{6}{|l|}{ Part-oriented style } \\
\hline \multicolumn{6}{|l|}{ Copy } \\
\hline Part-Oriented & 0.96 & 0.40 & $0.22^{*}$ & 2.88 & 0.05 \\
\hline Performance IQ & $<0.01$ & $<0.01$ & 0.01 & & \\
\hline \multicolumn{6}{|l|}{ Immediate Recall } \\
\hline Part-Oriented & 0.29 & 0.41 & 0.07 & 0.55 & 0.01 \\
\hline Performance IQ & $<-0.01$ & $<0.01$ & -0.04 & & \\
\hline \multicolumn{6}{|l|}{ Delayed Recall } \\
\hline Part-Oriented & 0.35 & 0.40 & 0.09 & 0.90 & 0.01 \\
\hline Performance IQ & $<-0.01$ & $<0.01$ & -0.07 & & \\
\hline
\end{tabular}

No significant association after applying Holm-Bonferroni correction. ${ }^{*} \mathrm{p}<0.05$. IQ: intelligent quotient 